\title{
A Study on the Relationship between Nutritional Status and Prevalence of Pneumonia and Diarrhoea among Preschool Children in Kushtia
}

\author{
Shaikh Shahinur Rahman ${ }^{1}$, Afroza Khatun ${ }^{1}$, Bably Sabina Azhar ${ }^{1}$, Hafizur Rahman ${ }^{1}$ \\ and Sabir Hossain ${ }^{2}$ \\ ${ }^{1}$ Department of Applied Nutrition and Food Technology, Islamic University, Kushtia, Bangladesh \\ ${ }^{2}$ Department of Biochemistry and Molecular Biology, Jahangirnogor University, Savar, Dhaka, \\ Bangladesh
}

Correspondence should be addressed to: Shaikh Shahinur Rahman; shahinanft@gmail.com

Received Date: 24 September 2013; Accepted Date: 20 March 2014; Published Date: 28 May 2014

Academic Editor: Mohammod Jobayer Chisti

Copyright @ 2014 Shaikh Shahinur Rahman, Afroza Khatun, Bably Sabina Azhar, Hafizur Rahman and Sabir Hossain. Distributed under Creative Commons CC-BY 3.0

\begin{abstract}
The prevalence of diarrhoea and pneumonia is quite alarming amongst children under 5 years of age who belong to low socioeconomic status. This study was carried out from January to December (2012) in Kushtia, and the total sample were boys (209) and girls (191). Anthropometric measurements were performed by standard methods National Centre for Health Statistics (NCHS). The prevalence of severe underweight, stunting and wasting ( $\leq-3 \mathrm{SD}$ ) were found in the sample data about $11 \%, 22 \%$ and $17 \%$ respectively; whereas the prevalence of pneumonia, diarrhea and both pneumonia \& diarrhea was found $53 \%, 44.50 \%$ and $38.75 \%$ respectively. The high prevalence of pneumonia (62.72\%) and frequency (1.85) were found in under 12 months age group, while diarrhea $(48.86 \%)$ and both pneumonia \& diarrhea $(45.45 \%)$ were found in 13-24 months age group. A greatest relationship was found between mother and child health status. About $89.26 \%$ mothers with poor health status have a sick child. Among the mothers with good health, the percentage of sick children was $45.73 \%$. In this study, $34.25 \%$ of children were found to be severe anemic, $40.25 \%$ of children were found to be moderately anemic and $25.50 \%$ were nonanemic. Our findings underscore the fact that even poor nutrition or marginal malnutrition can predispose children to pneumonia. Anemia also significantly increased the risk of pneumonia in children. Our study revealed that anemia might be a risk factor for lower respiratory tract infections including pneumonia; however further studies with statistical model is needed to confirm. This study also indicated that children with diarrhea were at increased risk of pneumonia.
\end{abstract}

Keywords: Pre-school children, pneumonia, diarrhea, anemia.

Cite this Article as: Shaikh Shahinur Rahman, Afroza Khatun, Bably Sabina Azhar, Hafizur Rahman and Sabir Hossain (2014), "A Study on the Relationship between Nutritional Status and Prevalence of Pneumonia and Diarrhoea among Preschool Children in Kushtia," Pediatrics Research International Journal, Vol. 2014 (2014), Article ID 805309, DOI: 10.5171/2014.805309 


\section{Introduction}

Children under 5 years should be taken a special care because they are most vulnerable and high risk group. Malnutrition, infectious diseases, diarrhea, pneumonia etc are very common in this group. About $12.5-15 \%$ of world populations are under 5 years age group and the mortality rate is $25-30 \%$ among the developing countries (Majlesi F et al., 2001). Childhood malnutrition is comparatively high in Southern Asia likely $45-48 \%$ in Bangladesh, India and Nepal, $38 \%$ in Pakistan and $30 \%$ in Sri Lanka (Peiris and Wijesinghe, 2010). More than $50 \%$ of child's death occurs due to diarrhoea, pneumonia, acute respiratory illness, malaria, or measles (Amy L. Rice et al., 2000). Pneumonia and diarrhea are the two leading cause of child death in the world (Black RE. et al., 2010; Dickens Onyango et al., 2012; J. Anthony G. Scott et al., 2008). About $21 \%$ and $17 \%$ deaths occur due to childhood pneumonia and diarrhea respectively (Onyango and Angienda, 2010; Williams BG, Gouws E et al., 2002). Every year more than 1.9 million children die due to pneumonia; whereas diarrhea kills about 4 million children (PIDS and IDSA, 2011; WHO, Media centre, 2012; Dickens Onyango et al., 2012). In the developing countries, annually, at least 1,500 million episodes of diarrhea and more than 150 million episodes of pneumonia occur in young children (Rudan I. et al., 2008; WHO, 1999). According to WHO (2006), an estimated of $98 \%$ children live in developing countries who die of pneumonia (WHO, 2006). Malnutrition and Diarrhoea increase the risk of pneumonia among young age group (Sania Ashraf et al., 2013; Coles CL et al., 2005). Dehydration caused by diarrhoea may also increase the risk of respiratory illnesses (Kalhoff $\mathrm{H}$., 2003). Reducing child mortality is one of the eight Millennium Development Goals (MDGs), which are the world's time-bound targets for reducing poverty in its various dimensions by 2015. Achieving this goal will require urgent action to reduce childhood pneumonia and diarrhoea deaths, which at present account for 19 percent of all under-five deaths. In Bangladesh enteric infections, infectious diseases and malnutrition are common, while maternal and infant mortality are extremely high due to the tropical climate, combined with the existence of large open water-bodies, dense population, poverty and poor access for the majority to reliable health services. Low birth weight, underweight, and lack of breastfeeding have been identified as risk factors for pneumonia (Victora CG, Kirkwood BR, Ashworth A, et al., 1999; O'Dempsey TJ, McArdle TF, Morris J et al., 1996). Thus, the aim of this study was to examine the health status of the children in Kushtia district, and observe the impact of malnourishment upon the high prevalence of diarrhoea and pneumonia infection among them.

\section{Methods and Materials}

This cross sectional survey was done in Kushtia district with the sample of 400 preschool going children in the session, January to December, 2012. In this study, the sample children (0-60 months) are selected randomly in urban \& rural area, and desirable data were collected from both mother and children through oral questionnaires, physical and clinical examination, dietary habit, anthropometric measurements etc, and the various disease associated with malnutrition were evaluated by detailed history \& clinical examination. The survey form was prepared in two sections. The first part was conducted in order to assess the nutritional status by taking anthropometric measurement and dietary history of the child, and the second part was prepared for examining the presence of any disease. Over 20 infrastructure items in and around the dwelling were examined in this survey.

\section{Data Analysis}

Data was coded and entered into a computer database, summarized and presented descriptively. Z-scores were calculated for height-for-age (H/A), weight-for-height $(\mathrm{W} / \mathrm{H})$ and weight-forage (W/A) using Epi Info software. Prevalence of malnutrition i.e. stunting, wasting and underweight was determined using the reference population defined by the National Centre for Health Statistics 
(NCHS) of the United States, as local reference standards are not available. The procedure of transforming the anthropometric data into Standard Deviation scores (SD) usually mentioned as $\mathrm{Z}$ - scores was adopted. The cut-off points used for the indicators are "-2 to -2.99 SD" for moderate and "-3SD and below" for severe state (Rosland S. Gibson, 1990). For the determination of nutritional status, a cross sectional study was conducted. It includes their economic and sociodemographic data, cultural practice, food habits, food beliefs and food prices (Derrick B Jelliffe, 1989). Data were analyzed by NCHS reference data.

\section{Result}

This study was conducted to investigate the relationship between nutritional status and incidence of pneumonia and diarrhea among under-5 aged rural and urban children with special reference to the socioeconomic status of parents. A total of four hundred children aged between 0-60 months were enrolled in this study.

Table 1 shows that the prevalence of pneumonia, diarrhea or both were $53.00 \%$, $44.50 \%$ and $38.75 \%$ respectively. The highest prevalence age group for pneumonia (62.72\%) was 0-12 months; whereas diarrhea (48.86\%) and both diarrhea \& pneumonia (45.45\%) were 13 24 months. On the other hand, the lowest prevalence rate of pneumonia, diarrhea and both pneumonia \& diarrhea were $44.44 \%, 41.07 \%$ and $31.94 \%$ respectively, and the age group were 49-60 months for diarrhea and 37-48 months for pneumonia and both pneumonia \& diarrhea.

Table 1: Distribution of Children with Mean Weight, Height and Mid-Upper Arm Circumference (MUAC) according to Age Group and Their Prevalence of Diarrhoea, Pneumonia or Both

\begin{tabular}{|c|c|c|c|c|c|c|c|c|c|}
\hline \multirow[t]{2}{*}{$\begin{array}{l}\text { Age } \\
\text { (month) }\end{array}$} & \multirow[t]{2}{*}{$\begin{array}{ll}\begin{array}{l}\text { No. } \\
\text { children }\end{array} & \text { of }\end{array}$} & \multirow{2}{*}{$\begin{array}{l}\text { Weig } \\
\text { ht } \\
(\mathrm{kg})\end{array}$} & \multirow[t]{2}{*}{$\begin{array}{l}\text { Height } \\
\text { (cm) }\end{array}$} & \multirow[t]{2}{*}{$\begin{array}{l}\text { MUAC } \\
(\mathrm{cm})\end{array}$} & \multirow{2}{*}{\begin{tabular}{l}
\multicolumn{2}{c}{$\begin{array}{r}\text { Suffering } \\
\text { Pneumonia }\end{array}$} \\
No \\
children of \\
(\% \\
Prevalence)
\end{tabular}} & \multirow{2}{*}{$\begin{array}{l}\text { from } \\
\text { Frequenc } \\
y\end{array}$} & \multicolumn{2}{|c|}{ Suffering from Diarrhoea } & \multirow{2}{*}{$\begin{array}{l}\text { Diarrhea \& } \\
\text { Pneumonia }\end{array}$} \\
\hline & & & & & & & $\begin{array}{l}\text { No of children } \\
\text { (\% Prevalence) }\end{array}$ & $\begin{array}{l}\text { Freq } \\
\text { uenc } \\
\text { y }\end{array}$ & \\
\hline $\begin{array}{l}0-12 \\
\text { Boys(\%) } \\
\text { Girls(\%) }\end{array}$ & $\begin{array}{l}68(17.00) \\
42(10.50)\end{array}$ & 7.4 & 65.22 & 10.34 & $69(62.72)$ & 1.85 & $47(42.72)$ & 1.17 & $45(40.90)$ \\
\hline $\begin{array}{l}13-24 \\
\text { Boys(\%) } \\
\text { Girls(\%) }\end{array}$ & $\begin{array}{l}47(11.75) \\
41(10.25)\end{array}$ & 11.3 & 76.76 & 11.43 & $47(53.40)$ & 1.70 & $43(48.86)$ & 1.70 & $40(45.45)$ \\
\hline $\begin{array}{l}25-36 \\
\text { Boys(\%) } \\
\text { Girls(\%) }\end{array}$ & $\begin{array}{l}35(8.75) \\
39(9.75)\end{array}$ & 12.10 & 81.35 & 12.14 & $37(50.00)$ & 1.65 & $34(45.94)$ & 1.46 & $27(36.48)$ \\
\hline $\begin{array}{l}37-48 \\
\text { Boys(\%) } \\
\text { Girls(\%) }\end{array}$ & $\begin{array}{l}35(8.75) \\
37(9.25)\end{array}$ & 14.3 & 89.43 & 13.96 & $32(44.44)$ & 1.30 & $31(43.05)$ & 1.30 & $23(31.94)$ \\
\hline $\begin{array}{l}49-60 \\
\text { Boys(\%) } \\
\text { Girls(\%) }\end{array}$ & $\begin{array}{l}24(6.00) \\
32(8.00)\end{array}$ & 16.8 & 96.35 & 13.93 & $27(48.21)$ & 1.50 & 23 (41.07) & 1.23 & $20(35.71)$ \\
\hline $\begin{array}{l}\text { Total } \\
\text { Boys(\%) } \\
\text { Girls(\%) }\end{array}$ & $\begin{array}{l}209(52.25) \\
191(47.75)\end{array}$ & 12.38 & 81.82 & 12.36 & $212(53.00)$ & & $178(44.50)$ & & $155(38.75)$ \\
\hline
\end{tabular}

Table-1 also shows the frequency of pneumonia and diarrhea according to age group 0-12, 13-24, 25-36, 37-48, and 49-60 months in which the frequency of pneumonia were $1.85,1.70,1.65,1.30,1.50$ and for diarrhea were 1.17, 1.70, 1.46, 1.30, and 1.23 respectively. It also depicts that among the children the mean weight, height and MUAC of children were 12.38 $\mathrm{kg}, 81.82 \mathrm{~cm}$ and $12.36 \mathrm{~cm}$ respectively. 
Table 2 represents the growth performance (underweight) of the children using the indicator-weight for age (W/A, Z score). It shows that $11.00 \%$ of the children were severely underweight (-3SD) and 36.00\% were moderately underweight $(-2.00$ to 2.99 SD). $19.00 \%$ of the children were mild underweight between -1.00 to -1.99 SD of the NCHS median and $34.00 \%$ children were normal.

Table 2: Nutritional Status of Different Age Group Children Based on Height, Weight and Age (Anthropometric Indices) Number in Parenthesis Indicates the Percentage of the Children

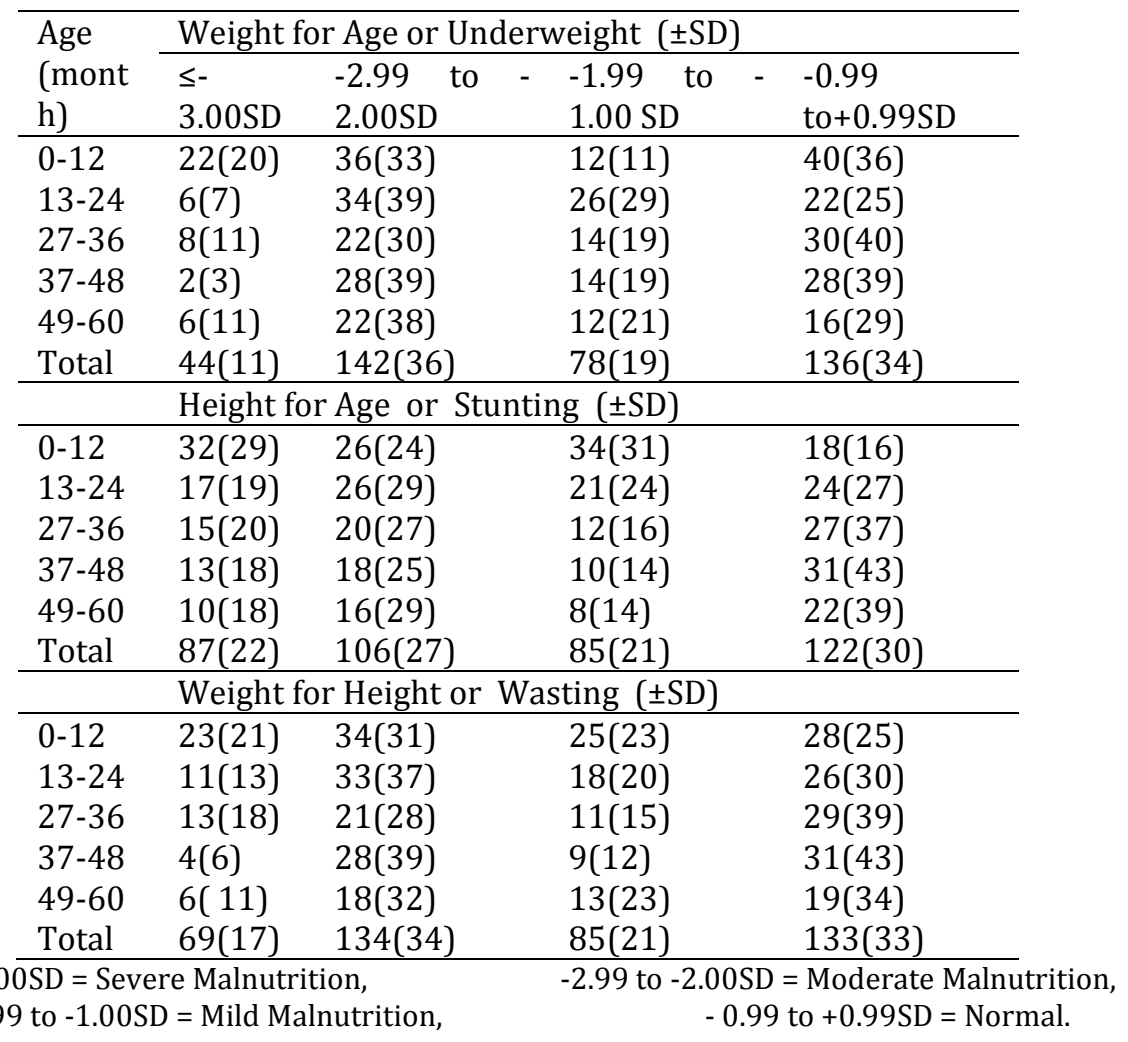

This table also shows that $30.00 \%$ of children height for age Z-score was between -0.99 to +0.99 SD of the NCHS median which indicates that they were normal. The prevalence of severe stunting $(<-3 \mathrm{SD})$ were found in the sample data about $22.00 \%$, while the prevalence of moderate ( -2.99 to-2.00) and mild stunting $(-1.99$ to $-1.00 \mathrm{SD})$ were $27.00 \%$ and $21.00 \%$ respectively. It also depicts the distribution of children's weight for height (Z-score) according to age group. Amongst all the children, $17.00 \%$ children was found as severely wasted in any age group, and $34.00 \%$ were moderately wasted (-2SD to $<-3 \mathrm{SD}$ ). $21.00 \%$ of the children were mild wasted, W/H- Z-score was between 1.00 to -1.99 SD of the NCHS median and $33 \%$ were normal.
Table 3 shows that $51.75 \%$ of mothers were in the age group 24-33 years, whereas $40.00 \%$ were in $14-23$ and only $8.25 \%$ were in the age range of $34-43$ years. Among the mothers, $87.25 \%$ have some common food taboos and $12.25 \%$ were not. $59.25 \%$ of mothers give their children colostrums after birth; whereas $40.75 \%$ of mothers didn't give colostrum. The table also shows that $86.25 \%$ of children have taken vaccine and $13.75 \%$ of children have not taken vaccine. A great relationship was found between mother and child health status. $89.26 \%$ of mothers with poor health status have sick children; whereas among the mothers with good health the percentage of sick children is $45.73 \%$. 
Table 3: Distribution of Mother according to Their Age Group, Maternal Nutrition Knowledge and Its Relation with Child Health (Data Collected from Hospital Report/Diagnostic Report)

\begin{tabular}{lc}
\hline Characteristics & No of mother $(\%)$ \\
\hline Age of mother(year) & $160(40.00)$ \\
$14-23$ & $207(51.75)$ \\
$24-33$ & $33(8.25)$ \\
$34-43$ & \\
Food taboos & $349(87.25)$ \\
Yes & $51(12.75)$ \\
No & \\
Breast Feeding (Colostrum) & No. of Children (\%) \\
Yes & $237(59.25)$ \\
No & $163(40.75)$ \\
Full vaccination schedule & \\
Yes & \\
No & $345(86.25)$ \\
& $55(13.75)$ \\
Maternal health status & \\
Good health mother (223) & No. of sick child (\%) \\
Poor health mother (177) & $102(45.73)$ \\
& $158(89.26)$ \\
Hb level & \\
$<7$ (Severe anemia) & $137(34.25)$ \\
$7-10.9$ (Moderate anemia) & $161(40.25)$ \\
Infection $\geq 11$ (Normal) & $102(25.50)$ \\
Diarrhoea & \\
Pneumonia & $178(44.50)$ \\
\hline
\end{tabular}

This table also represents the distribution of children by haemoglobin (Hb) level. In this study, $25.50 \%$ of the children were found to be normal ( $\mathrm{Hb} 10.9-11$ ), 40.25\% and $34.25 \%$ of the children were found to be moderate and severe anemic, respectively. During the period of survey, the most common diseases that are observed and confirmed by taking history are listed in the table. Among those diseases the most prevalence are diarrhea (44.50\%), pneumonia (53.00\%, and other diseases (48.75\%).

Table 4 depicts that $44.00 \%$ of the parents had no formal primary education, $39.75 \%$ received education below Secondary School Certificate (S.S.C) and 16.25\% received education up to S.S.C. It also shows that most of the parents of study subjects were daily labor (46.75\%); whereas $29.75 \%$ and $23.50 \%$ were government and private service, respectively. Monthly income for $27.25 \%$ of households were TK $<3000,21.75 \%$ of households were over 5000 and $51 \%$ of households earned TK 3100-5000 per month. $21.25 \%$ of the households were less than 4 persons, whereas $39.00 \%$ and $39.75 \%$ of families have greater than 4- 5 and 5 persons, respectively. 
Table 4: Determination of Parent's Socio-Economic Status according to Their Education, Occupation, Living Status and Their Consciousness about Baby Food

\begin{tabular}{|c|c|}
\hline Characteristics & $\begin{array}{c}\text { No of Parents } \\
(\%)\end{array}$ \\
\hline \multicolumn{2}{|l|}{ Level of education } \\
\hline Primary & $176(44.00)$ \\
\hline Below secondary school & $159(39.75)$ \\
\hline certificate (S.S.C) & $65(16.25)$ \\
\hline \multicolumn{2}{|l|}{ Up to S.S.C } \\
\hline Types of occupation & $187(46.75)$ \\
\hline Day labour & $119(29.75)$ \\
\hline Govt.service & $94(23.50)$ \\
\hline \multicolumn{2}{|l|}{ Private service } \\
\hline Range of monthly income & $109(27.25)$ \\
\hline (Taka) & $204(51.00)$ \\
\hline$<3000$ & 87 (21.75) \\
\hline \multicolumn{2}{|l|}{$3000-5000$} \\
\hline$>5000$ & $159(39.75)$ \\
\hline Level of family size & $156(39.00)$ \\
\hline$>5$ & $85(21.25)$ \\
\hline \multicolumn{2}{|l|}{$4-5$} \\
\hline$<4$ & $139(34.75)$ \\
\hline Type of living house & $156(39.00)$ \\
\hline Pucca (Building) & 105 (26.25) \\
\hline \multicolumn{2}{|l|}{ Tinned/ semi pucca } \\
\hline Kacha (Mud made building) & $235(58.75)$ \\
\hline Type of latrine used & $144(36.00)$ \\
\hline Sanitary & $21(5.25)$ \\
\hline \multicolumn{2}{|l|}{ Kacha } \\
\hline Others & $111(27.75)$ \\
\hline Money spent on baby food & $196(49.00)$ \\
\hline purpose & $93(23.25)$ \\
\hline \multicolumn{2}{|l|}{ Low (Little amount) } \\
\hline Very little amount & $296(74.00)$ \\
\hline Acceptable amount & $104(26.00)$ \\
\hline Source of drinking water & - \\
\hline \multicolumn{2}{|l|}{ Tub well } \\
\hline \multicolumn{2}{|l|}{ Supply water } \\
\hline Others & \\
\hline
\end{tabular}

This table also showed the type of house which reflects socioeconomic status of any community. Amongst the study population, $39.00 \%$ of families lived in tin-shed house; whereas $26.25 \%$ in mud shed and only
$34.75 \%$ had buildings to live in. On the other hand, $36.00 \%$ used unsanitary latrines and $58.75 \%$ used sanitary latrines, and only $5.25 \%$ households have no access to toilet facilities. 
Table 4 also shows that only $23.25 \%$ of parents spent their money on baby food purpose per month; whereas $49.00 \%$ of parents spent very low amount. Again, 74\% of families use tube-well for drinking water while $26 \%$ use supply water.

Table 5 depicts the prevalence of malnutrition (growth retardation) by using different anthropometric indicators.
Amongst all the children, higher proportion of children $47.00 \%$ were found to be malnourished (under weight) using W/A as an indicator in the age range of 0-60. Amongst all the subjects, the prevalence of wasting and stunting was $51.00 \%$ and $49.00 \%$, respectively. The age group $0-12$ months shows the highest prevalence of wasting under weight and stunting.

Table 5: Percent Incidence of Stunting, Wasting and Underweight by Age Group for Survey

\begin{tabular}{cccc}
\hline \multirow{2}{*}{$\begin{array}{c}\text { Age } \\
\text { (months) }\end{array}$} & Stunted & Wasted & Underweight \\
\cline { 2 - 4 } & $\begin{array}{c}\text { (-2SD or } \\
\text { below) }\end{array}$ & $\begin{array}{c}\text { (-2SD or } \\
\text { below) }\end{array}$ & $\begin{array}{c}\text { (-2SDor } \\
\text { below) }\end{array}$ \\
\hline $0-12$ & 53 & 52 & 53 \\
$13-24$ & 48 & 50 & 46 \\
$25-36$ & 47 & 46 & 41 \\
$37-48$ & 43 & 45 & 42 \\
$49-60$ & 47 & 43 & 49 \\
Total & 49 & 51 & 47 \\
\hline
\end{tabular}

Figure 1 shows the distribution of children by different ranges of MUAC. In this study $24 \%$ of the children were found to be normal $(14.5 \mathrm{~cm}), 14.25 \%, 36.00 \%$, \&
$25.75 \%$ of the children were found to be mild, moderate and severe malnutrition, respectively in MUAC measurement.

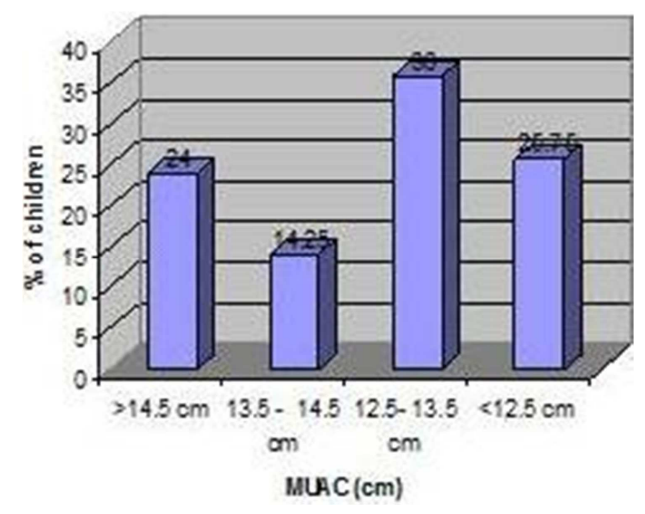

Figure-1: Percent Distribution of Children by Different Categories of MUAC

\section{Discussion}

The prevalence of diarrhoea and pneumonia is quite alarming amongst children under 5 years of age who belong to low socioeconomic status. While it is widely recognized that diarrhea and pneumonia are the major cause of morbidity and mortality among children in developing countries, especially in
Bangladesh and it is affected by several socio-economic, environmental and behavioral factors. According to UNICEF and WHO, pneumonia and diarrhea kill 1.2 million of children every year than any other illness - more than AIDS, malaria and measles are combined (WHO, Media centre, 2012). This is a prospective community based cross sectional study performed in urban \& rural areas of Kushtia district to 
find out the relationship between nutritional status and incidence of pneumonia and diarrhea among under-5 years children. This study was conducted on 400 children (0-60 months) of whom 209 were male and 191 were female.

In our study, the parents' educational level was low, only $16.25 \%$ have school certificate and $51 \%$ of the family income was TK.3000-5000 per month which cannot ensure proper health and nutrition to a medium size family (4-5 persons) in our country. Amongst the study population $39.00 \%$ of families lived in tin shed house, whereas $26.25 \%$ in mud shed and $34.75 \%$ had buildings to live in. Most of the study subjects $(58.75 \%)$ used the sanitary latrines, and $74 \%$ of the households use tube well water for drinking; but none of them boil water before drinking. It has been showed that most of the children were full vaccination schedule (86.25\%) and $59.25 \%$ of mothers give their children colostrums after birth.

Malnutrition affects a large proportion of children under the age of 5 years. In Kushtia, approximately $49 \%$ were stunted (height-for-age Z-score < -2 SD), about $51 \%$ were wasted (weight-for-height Zscore < -2 SD) and about 47\% were underweight (weight-for-age Z-score $<-2$ SD). In this study $34.25 \%$ of children were found to be severe anemic, $40.25 \%$ of children were found to be moderately anemic and $25.50 \%$ were non-anemic. A great relationship was found between the mother and child health status. About $89.26 \%$ of mothers with poor health status have sick child whereas among the mothers with good health, the percentage of sick child was $45.73 \%$. The prevalence of diarrhoea and pneumonia was found $44.50 \%$ and $53 \%$ respectively.

Diarrhoea occurs in all age groups especially in the developing countries, but highly prevalent among children in the first two years of life (Patwari AK, Manorama Deb and Ridie Duidyaj, 1993). In our study, the maximum prevalence $(48.86 \%)$ of diarrhea was found in the age of two. The infants aged less than 12-24 months experienced a higher frequency (1.70) of persistent diarrhoea. A high prevalence of persistent diarrhoea among the young infants in our study may be related to the early exposure to heavy microbial load and immaturity of the gut immune system at early infancy.

UNICEF and WHO have estimated that 1.3 million of child deaths could be averted every year if pneumonia prevention and treatment interventions were universally delivered (UNICEF, June 2012). In our study, the higher prevalence $(62.72 \%)$ and frequency (1.85) of pneumonia was found in under 12 months of age. The prevalence of both diarrhoea and pneumonia was estimated in 38.75\%. Our result demonstrated that the prevalence of diarrhea and pneumonia was found higher in less than 0-24 months aged children than that of 48-60 months. But actually, the prevalence of diarrhoea and pneumonia in 48-60 months aged children should be higher because they already passed more time span of their life. Most of the mothers may forget the occurrence of the disease of their earlier days. Our findings underscore the fact that even poor nutrition or marginal malnutrition can predispose children to pneumonia. Anemia also significantly increases the risk of pneumonia in children (Harris et al. 2011). Anemia also significantly increases the risk of pneumonia in children which indicate that anemia might be a risk factor for lower respiratory tract infections including pneumonia; however further studies are needed to confirm this association.

On the basis of the malnutrition-infection cycle described by Scrimshaw and San Giovanni, increased frequency of diarrhea result in poor nutritional status, which in turn predispose to pneumonia. Our results indicated that children with diarrhea were at increased risk of pneumonia. We have identified potentially modifiable factors that may contribute to the high prevalence of pneumonia in the children living in urban and rural areas: anemia, stunting, and low birth weight. The ddevelopment and implementation of effective antenatal and nutritional intervention programs for children and community-based educational programs for mothers are likely to improve 
all three factors, decreasing the risk of pneumonia. More researches are needed on the causes of diarrhoea and pneumonia in this community to determine whether they are amenable to nutritional intervention.

\section{Acknowledgement}

The authors are thankful to the Dept of Applied Nutrition and Food Technology and to the participants of this study at Kushtia who shared their valuable time to fill their oral questionnaire and various types of anthropometric measurement.

\section{References}

Ashraf, S., Huque, M. H., Kenah, E., Agboatwalla, M. \& Luby, S. P. (2013). "Effect of Recent Diarrhoeal Episodes on Risk of Pneumonia in Children under the Age of 5 Years in Karachi, Pakistan," International Journal of Epidemiology.

Black, R. E., Cousens, S., Johnson, H. L., Lawn, J. E., Rudan, I., Bassani, D. G., Jha, P., Campbell, H., Fischer-Walker, C., Cibulskis, R., Eisele, T., Liu, L. \& Mathers, C. (2010). "Global, Regional, and National Causes of Child Mortality in 2008: A Systematic Analysis," The Lancet, 2010; 375: 19691987.

Coles, C. L., Fraser, D., Givon-Lavi, N. et al. (2005). "Nutritional Status and Diarrheal Illness as Independent Risk Factors for Alveolar Pneumonia," American Journal of Epidemiology; 162:999-1007.

Dickens Onyango, Gideon Kikuvi, Evans Amukoye \& Jared Omolo (2012). "Risk Factors of Severe Pneumonia among Children Aged 2-59 Months in Western Kenya: A Case Control Study," The Pan African Medical Journal - ISSN 1937-8688. http://www.panafrican-medjournal.com/content/article/13/45/full

Harris, A. M. et al. (2011). "Air Pollution and Anemia as Risk Factors for Pneumonia in Ecuadorian Children: A Retrospective Cohort Analysis," Environmental Health 10:93.
Jelliffe, D. B. \& Jelliffe, E. F. (1989). "Community Nutritional Assessment," Oxford University Press, Direct Assessment of Nutritional Status, Pp.13-30.

Kalhoff, H. (2003). "Mild Dehydration: A Risk Factor of Broncho-Pulmonary Disorders?," European Journal of Clinical Nutrition;57:S81-S87.

Majlesi, F., Nikpoor, B., Golestan, B. \& Sadre, F. (2001). "Growth Chart Study in Children Under 5 Years Old in Rural Area of Khoramabad Province," Iranian Journal of Public Health, Vol. 30, Nos. 3-4, PP. 107110.

O'Dempsey, T. J. D., Mcardle, T. F., Morris, J. et al. (1996). "A Study of Risk Factors for Pneumococcal Disease among Children in a Rural Area of West Africa," International Journal of Epidemiology; 25:885-93.

Onyango, D. M. \& Angienda, P. O. (2010). "Epidemiology of Waterborne Diarrhoeal Diseases among Children Aged 6-36 Months Old in Busia - Western Kenya," International Journal of Biological and Life Sciences 6:2.

Patwari, A. K., Deb, M. \& Dudeja, M. et al. (1993). "Clinical and Laboratory Predictors of Invasive Diarrhoea in Children Less than Five Years Old," Journal of Diarrhoeal Diseases Research, 11 (4): 211-216.

Pediatric Infectious Diseases Society (PIDS) and the Infectious Diseases Society of America (IDSA). (2011). 'Guidelines for Treating Pneumonia in Children,' Science News Aug. 31.

Peiris, T. D. R. \& Wijesinghe, D. (2010). "Nutritional Status of Under 5 Year-Old Children and Its Relationship with Maternal Nutrition Knowledge in Weeraketiya DS Division of Sri Lanka," Tropical Agricultural Research Vol. 21(4): $330-339$.

Rice, A. L., Sacco, L., Hyder, A. \& Black, R. E. (2000). "Malnutrition as an Underlying Cause of Childhood Deaths Associated with Infectious Diseases in Developing 
Countries," Bulletin of the World Health Organization, vol.78 n.10 Genebra Jan.

Rosland S. Gibson. (1990). 'Principle of Nutritional Assessments; Nutritional Assessment System,' Oxford University Press, Pp350-356.

Rudan, I., Boschi-Pinto, C., Biloglav, Z., Mulholland, K. \& Campbell, H. (2008). "Epidemiology and Etiology of Childhood Pneumonia," Bulletin of the World Health Organization; 86(5):408-416.

Scott, J. A. G., Brooks, W. A., Peiris, J. S. M., Holtzman, D. \& Mulholland, E. K. (2008). "Pneumonia Research to Reduce Childhood Mortality in the Developing World," The Journal of Clinical Investigation; 118(4): 1291-1300.

United Nations Children's Fund (UNICEF), (June 2012). 'Pneumonia and Diarrhoea: Tackling the Deadliest Diseases for the World's Poorest Children,' www.childinfo.org/publications
Victora, C. G., Kirkwood, B. R., Ashworth, A. et al. (1999). "Potential Interventions for the Prevention of Childhood Pneumonia in Developing Countries: Improving Nutrition," American Society for Clinical Nutrition; 70:309-20.

WHO (2006). World Health Statistics (2006), Geneva: World Health Organization.

WHO, Media Centre (2012). Pneumonia, Fact Sheet $N^{\circ} 331$.

Williams, B. G., Gouws, E. et al. (2002). "Estimates of World-Wide Distribution of Child Deaths from Acute Respiratory Infections," The Lancet Infectious Diseases; 2(1):25-32. 